\title{
Correction: Complete remission of seronegative rheumatoid arthritis following haplo-identical stem cell transplantation for peripheral T-cell lymphoma
}

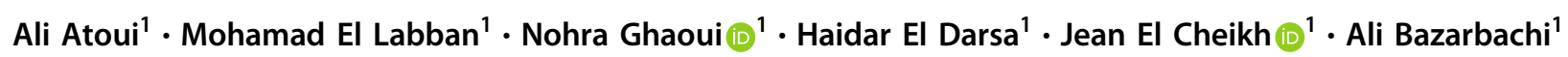

Published online: 4 October 2019

(c) Springer Nature Limited 2019

\section{Correction to: Bone Marrow Transplantation}

https://doi.org/10.1038/s41409-019-0635-9
Following the publication of this Article, it was noted that the author name Jean Cheikh was listed incorrectly. This has been corrected to Jean El Cheikh.

Ali Bazarbachi

bazarbac@aub.edu.lb

1 Department of Internal Medicine, American University of Beirut, Medical Center, 113-6044 Beirut, Lebanon 